\title{
Unlocking fiscal space of expanding the health workforce in district health systems in Uganda in the context of PEPFAR transition
}

\author{
Henry Zakumumpa ( $\nabla$ zakumumpa@yahoo.com ) \\ University of the Western Cape https://orcid.org/0000-0002-8169-1151 \\ Joseph Rujumba \\ Makerere University
}

Amde Woldekidan

University of the Western Cape

Respicius Damian Shumbusho

University of Dar es salaam

Freddie Ssengooba

Makerere University

\section{Research Article}

Keywords: Human Resources for Health, health systems, decentralization, HIV, donor transition, Implementation Research, overseas development assistance

Posted Date: March 8th, 2021

DOl: https://doi.org/10.21203/rs.3.rs-301407/v1

License: (c) (1) This work is licensed under a Creative Commons Attribution 4.0 International License. Read Full License 


\section{Abstract}

Although expanding fiscal space for health worker recruitments could reduce workforce shortages in SubSaharan Africa, effective strategies for achieving this are still unclear. We aimed to understand the process of transitioning health workers (HWs) from PEPFAR to Government of Uganda (GoU) payrolls and to explore the facilitators and barriers encountered in increasing domestic financial responsibility for absorbing this transitioned workforce. We conducted a multiple case-study of 10 (out of 87) districts in Uganda which received PEPFAR support between 2013 and 2015 to expand their health workforce. We purposively selected eight districts with the highest absorption rates ('High absorbers') and two with the lowest absorption rates ('Low absorbers'). A total of 66 interviews were conducted with high-level officials in three Ministries of Finance, Health and Public Service $(n=14)$, representatives of PEPFAR implementing organizations $(n=16)$, District Health Teams $(n=15)$ and facility managers $(n=22)$.

Twelve focus groups were conducted with $87 \mathrm{HWs}$ absorbed on GoU payrolls. We utilized the Consolidated Framework for Implementation Research (CFIR) to guide thematic analysis.

At sub-national level, facilitators of transition in 'high absorber' districts were identified as the presence of transition 'champions', prioritizing HWs in district wage bill commitments, host facilities providing 'bridge financing' to transition workforce during salary delays and receiving donor technical support in district wage bill analysis- attributes which were absent in "low absorber' districts. At national-level, multi-sectoral engagements (incorporating the influential Ministry of Finance), developing a joint transition road map, aligning with GoU salary scales and recruitment processes emerged as facilitators of the transition process.

Overall, PEPFAR support acted as a catalyst for increasing GoU and facility-level budget allocations towards expanding the health workforce in focus districts in Uganda. Our case-studies offer implementation research lessons on effective donor transition and insights into pragmatic strategies for expanding fiscal space for health in a low-income setting.

\section{Introduction}

Health workforce shortages constitute a fundamental barrier to the attainment of health-related sustainable development goals (SDGs) in Sub-Saharan Africa (SSA) (Freer 2017; Miseda et al. 2017). It is estimated that health worker vacancies are as high as $59-70 \%$ in several countries in SSA (Zakumumpa et al. 2016; Jaskiewicz et al. 2016; Vermund et al. 2012).

In countries with decentralized health systems in SSA, health workforce recruitments have been devolved from the central government to sub-national administrative units commonly referred to as districts in Ghana, Nigeria, Tanzania and Uganda (Abimbola et al. 2019; Sumah et al. 2019; Bossert et al. 2002; Munga et al. 2009; Sakyi et al. 2011).

Decentralized health worker recruitments in SSA is however beset by a myriad of institutional constraints. These include; delays in recruitment owing to cumbersome and lengthy administrative procedures, the 
ubiquitous 'vacancies but no wage bill' constraint, shortage of pay roll analysis expertise and increasingly dysfunctional district recruitment committees (Sumah and Baatiema 2019; Munga et al. 2009; Mbemba et al. 2016 ; Sakyi et al. 2011; Frumence et al. 2013).

In Uganda, decentralization was a part of governance reforms that date as far back as 1992 (Tashobya et al. 2016; Awortiwi, 2010). Health sector decentralization was formally provided for under the 1995 national constitution and further operationalized in the Local Government Act of 1997 (Tashobya et al. 2016). Uganda's district health system comprises of a district hospital and lower-level primary care health facilities (Alonso-Garbayo et al. 2017). In 2014, management of the public sector payroll and salary processing system was further decentralized to districts (Lwanga et al. 2018). District recruitment bodies known as 'district service commissions' conduct interviews and selections of health workers. However, devolved recruitment, in practice, is a shared responsibility between the districts (which declare vacancies and make recruitment decisions) and relevant central government line ministries such as Finance and Public Service which commit funds to the public sector wage bill. There exists a heavy dependence by districts on central government grants for both capital development and basic operational funds (AlonsoGarbayo et al. 2017).

Health worker shortages are pervasive at all levels of the health system in Uganda (Zakumumpa et al. 2017). In 2012, the Uganda government implemented an aggressive health workforce recruitment program known as 'the surge' in which 7,112 health workers were recruited to plug severe staffing gaps at the primary care level (Jaskiewicz et al. 2016). Specifically, health workers were recruited at the level of Health Centre IVs (sub-district) and Health Centre IIIs (sub-county). However, severe staffing gaps remained at the level of district hospitals which have relatively high HIV client loads (Zakumumpa et al. 2016). In response to these staffing gaps, and in order to accelerate progress towards HIV epidemic control in Uganda, PEPFAR developed a 3-year 'Human Resources for Health Support Program' in 2013 that was implemented in 87 focus-districts (USAID,2019). According to the implementation plan, the health workers would be initially recruited on contract by PEPFAR for a period of two years but would subsequently be absorbed into the mainstream public service as soon as fiscal space allowed. A total of 3,154 health workers were recruited by PEPFAR in Uganda between 2012 and 2015. Of these, 694 were enrolled onto the Government of Uganda (GoU) payroll between 2013 and 2017 (USAID,2019). An additional 1,965 health workers were expected to be transitioned to GoU in a phased manner between 2017 and 2020.

There has been increasing international assistance in addressing the human resources for health crisis in SSA in the quest to sustain public health gains registered during periods of donor support and to ensure the long-term sustainability of these outcomes during situations of declining donor aid (Micah et al. 2018). This has motivated fiscal space analyses by external donors and recipient governments with a view to increase reliance on domestic financing (Bennet et al. 2015; Resch and Hecht 2018; Burrows et al. 2016; Amaya et al. 2014; Vorgus et al. 2014, Gotsadze et al. 2019). Fiscal space has been defined as 'the capacity of government to provide additional budgetary resources for a desired purpose without any prejudice to the sustainability of its financial position' (Heller, 2006). As donors like PEPFAR reduce their 
financial support to workforce costs, little is known about which factors hinder or facilitate the expansion of fiscal space for health worker recruitments within the Government. These data are critical to understanding the dynamics involved, and strategies needed for increasing domestic financial responsibility and local ownership by recipient countries (Bennet et al. 2015; Resch and Hecht 2018; Burrows et al. 2016; Amaya et al. 2014; Vorgus et al. 2014; Vermund et al. 2012; Palen et al. 2012).

Although there is an accumulating evidence base on the notion of decision space in district health systems, in general (Bossert and Mitchell 2011; Henrikson et al. 2016; Liwanag et al. 2018; Bulthuis et al. 2020), and around Human Resources for Health in particular (Alonso-Garbayo et al. 2017; Sumah and Baetia 2019), there is little empirical attention to the prospect of creating fiscal space for expanding the health workforce in decentralized settings in low-income countries. We aimed to understand the process of health worker transition from PEPFAR to Uganda Government payrolls and to explore the facilitators and barriers encountered in increasing domestic financial responsibility for this transition.

\section{Materials And Methods}

\section{Research Design}

We utilized a qualitative case-study research design. Case-studies are recommended for an in-depth understanding of complex phenomena within organizations (Gilson 2012; Yin, 1993). We conducted a multiple case-study of 10 districts in Uganda categorized into two a) Eight districts with the highest rates of absorption of health workers recruited with PEPFAR support dubbed 'high absorbers' cases b) Two districts with the lowest absorption rates or the 'low absorbers'cases. We then conducted a comparative analysis across the two categories of cases with regard to facilitators and barriers to health worker transition.

\section{Case-studies selection}

The ten case-study districts were purposively selected from 87 districts in Uganda which received PEPFAR support in recruiting health workers between 2013 to 2017.

Study districts were purposively selected based on secondary analyses of databases in the Human Resources Information System (HRIS) and a locally-based international PEPFAR implementing organization's databases of health workers recruited between 2015 and 2017.

From these databases, we selected districts with the highest number of health workers transitioned from PEPFAR to Government of Uganda payrolls. Table 1 shows we selected the districts with the highest number of health workers transitioned from each of eight geographic sub-regions as defined by the Uganda Bureau of Statistics (Iganga, Sheema, Apac, Kasese, Napak, Nwoya, Tororo and Kampala) and based on HIV burden (which was the key focus of PEPFAR support). We then selected two districts with the lowest number of health workers absorbed onto their pay roll (Nakaseke and Bushenyi). Each of the two districts had absorbed only one health worker since 2013 when PEPFAR's health workforce transition program commenced in Uganda. 
Table 1: Characteristics of Case-study Districts

\begin{tabular}{|c|c|c|c|}
\hline $\begin{array}{l}\text { Geographic Sub- } \\
\text { region of Uganda }\end{array}$ & District & $\begin{array}{l}\text { HIV } \\
\text { Prevalence } \\
\text { (\%)[12] }\end{array}$ & Inclusion Criteria \\
\hline South Western & Sheema & 7.7 & $\begin{array}{l}\text { High number of transitioned HWs \& high } \\
\text { HIV prevalence }\end{array}$ \\
\hline East Central & Iganga & 4.4 & $\begin{array}{l}\text { High number of transitioned HWs, mixed } \\
\text { rural -urban }\end{array}$ \\
\hline Mid- East & Tororo & 4.8 & $\begin{array}{l}\text { High number of transitioned HWs \& cross } \\
\text { border dynamics, mainly urban }\end{array}$ \\
\hline Mid-West & Kasese & 5.5 & $\begin{array}{l}\text { High number of transitioned HWs \& cross } \\
\text { border dynamics, mainly urban }\end{array}$ \\
\hline Central 2 & Mubende & 7.4 & $\begin{array}{l}\text { High number of transitioned HWs \& high } \\
\text { HIV prevalence }\end{array}$ \\
\hline Mid North & $\begin{array}{l}\text { Nwoya } \\
\text { and } \\
\text { Apac }\end{array}$ & 7.0 & $\begin{array}{l}\text { High number of transitioned HWs \& high } \\
\text { HIV prevalence, largely rural }\end{array}$ \\
\hline North East & Napac & 3.4 & $\begin{array}{l}\text { High number of transitioned HWs } \& \text { hard to } \\
\text { reach, rural }\end{array}$ \\
\hline Kampala & Kampala & 6.6 & $\begin{array}{l}\text { Capital city\& houses many agencies } \\
\text { involved in transition planning }\end{array}$ \\
\hline
\end{tabular}

\section{Conceptual framework}

We utilized an implementation research lens (Proctor et al. 2009) to better understand the process of transitioning health workers from PEPFAR to Uganda Government payrolls and in order to explore the facilitators and barriers involved in this process. More specifically, we adopted the Consolidated Framework for Implementation Research (CFIR) as the analytical framework underpinning this study (Damschroder et al. 2009). The CFIR is a 'meta-theoretical' framework that was informed by earlier implementation research frameworks and is derived from a robust systematic review of factors influencing effective or successful implementation of interventions (Means et al. 2020). The CFIR framework provides a multi-level analysis lens that entails 39 constructs categorized under five 'domains' (Intervention characteristics, outer setting, inner setting, characteristics of individuals, and process of implementation). The CFIR framework guided this study in three ways. It informed the diverse range of study participants selected for this study especially those involved in the transition of the contract workforce onto the public sector payroll. It helped in constructing our qualitative interview guides during data collection and provided an overarching deductive thematic framework for our synthesis and interpretation of study findings and in their presentation (Means et al. 2020).

\section{Data collection}

In keeping with the CFIR framework's multi-level analysis lens, we selected study participants involved in the transition process at the policy \& planning, programmatic and implementation levels; a) national-level policy \& planning actors e.g. sector ministry officials (Ministry of Health, Finance and Public Service) and PEPFAR as well as its 'implementing partner (IP)' playing the overall national coordination function of overseeing the transition process b) Sub-national operational-level actors (e.g. District Health Officers, District personnel officers and PEPFAR implementing organizations at the sub-national operational level) 
c) Facility-level actors (Hospital administrators and the Principal Nursing Officers (Head Nurse) and transitioned health workers across diverse cadres. The category of participants is shown in Table 2.

Table 2

Category of participants

\begin{tabular}{|c|c|c|c|}
\hline Geographic Sub-region of Uganda & District & $\begin{array}{l}\text { HIV } \\
\text { Prevalence } \\
(\%)[12]\end{array}$ & Inclusion Criteria \\
\hline South Western & Sheema & 7.7 & $\begin{array}{l}\text { High number of transitioned HWs } \\
\text { \& high HIV prevalence }\end{array}$ \\
\hline East Central & Iganga & 4.4 & $\begin{array}{l}\text { High number of transitioned HWs, } \\
\text { mixed rural -urban }\end{array}$ \\
\hline Mid- East & Tororo & 4.8 & $\begin{array}{l}\text { High number of transitioned HWs } \\
\& \text { cross border dynamics, mainly } \\
\text { urban }\end{array}$ \\
\hline Mid-West & Kasese & 5.5 & $\begin{array}{l}\text { High number of transitioned HWs } \\
\& \text { cross border dynamics, mainly } \\
\text { urban }\end{array}$ \\
\hline Central 2 & Mubende & 7.4 & $\begin{array}{l}\text { High number of transitioned HWs } \\
\text { \& high HIV prevalence }\end{array}$ \\
\hline \multirow[t]{2}{*}{ Mid North } & $\begin{array}{l}\text { Nwoya } \\
\text { and }\end{array}$ & 7.0 & $\begin{array}{l}\text { High number of transitioned HWs } \\
\& \text { high HIV prevalence, largely } \\
\text { rural }\end{array}$ \\
\hline & Apac & & \\
\hline North East & Napac & 3.4 & $\begin{array}{l}\text { High number of transitioned HWs } \\
\& \text { hard to reach, rural }\end{array}$ \\
\hline Kampala & Kampala & 6.6 & $\begin{array}{l}\text { Capital city\& houses many } \\
\text { agencies involved in transition } \\
\text { planning }\end{array}$ \\
\hline Respondent type & Round 1 & Round 2 & Total \\
\hline $\begin{array}{l}\text { High-level sector ministry } \\
\text { technocrats }\end{array}$ & 14 & 0 & 14 \\
\hline District Health Team leaders & 12 & 3 & 15 \\
\hline Facility in-charges/ managers & 18 & 4 & 22 \\
\hline $\begin{array}{l}\text { Representatives of regional-based } \\
\text { PEPFAR Implementing Partners (IPs) }\end{array}$ & 11 & 2 & 13 \\
\hline $\begin{array}{l}\text { U.S. embassy program officers } \\
\text { (USAID and CDC) }\end{array}$ & 3 & 0 & 3 \\
\hline Focus Group Discussions & 6 & 2 & 15 \\
\hline Transitioned health workers & 75 & 12 & 87 \\
\hline
\end{tabular}


We conducted 15 face-to-face Key Informant Interviews (KIIs) with national-level actors who had 'insider' insights into the health worker transition process right from inception (e.g. during signing of MoUs) such as the overall coordinating PEPFAR implementing organization, program officers in the United States embassy in Uganda and high-level technocrats in the line Ministries of Health, Finance and Public Service who were directly involved in the inception meetings and in the consensus building between PEPFAR and the Uganda Government around absorption of health workers after their two-year contract period.

We then conducted 24 in-depth interviews (IDIs) with district-level actors in 10 case-study districts who were directly involved in the implementation of health workforce transition at the sub-national level or with in their decentralized settings. These included the District Health Officers and District Human Resources Officers. The interview guide used in our interviews was constructed around the five major CFIR-derived domains (Process of implementation, Intervention characteristics, outer setting, inner setting, Characteristics of Individuals). This overarching framework helped in eliciting the facilitators and barriers to health worker transition. Data were collected over two rounds. For the 'high absorber' cases, data were collected between June and September 2018 (round 1) and January to March 2020 (round 2) among the 'low absorber' case districts.

Twelve focus group discussions (FGDs) were conducted with 87 health workers who were transitioned onto the public pay roll in the case-study districts to better understand transition enablers and barriers from their perspective. The FGDs were conducted on-site at 10 district hospitals. The interviews were conducted in English by $\mathrm{HZ}$ and JR with the assistance of four research assistants who operated the recorder and took notes.

To augment respondent data, we conducted a desk review of relevant documents such as 'PEPFAR's Human Resources for Health(HRH) Support for Recruitment - Implementation plan of April 2013'. We reviewed written memos from two central government line Ministries of Public Service and Health addressed to district local government leaders urging them to absorb the health workforce recruited with PEPFAR support.

\section{Data analysis}

Qualitative data were analyzed in line with the procedures recommended by Miles and Huberman (1994). Interviews were recorded in English, transcribed verbatim into text transcripts by four research assistants. Data were analyzed, in an iterative process, involving four major steps; a) Data familiarization: $\mathrm{HZ}, \mathrm{JR}$ read the interview transcripts multiple times) b) Developing a coding framework. We adopted the five CFIR-derived domains (Intervention characteristics, outer setting, inner setting, characteristics of individuals, and process of implementation) as an overarching deductive thematic framework as well as inductively, from the data (Fereday and Muir-Cochrane, 2006) c) Data abstraction of the coded data into thematic categories while engaging in a constant comparative analysis across the two categories of cases of 'High absorber' and 'lower absorber' districts (Glaser and Straus, 1999) d) Overall interpretation and synthesis: The final analyses were reached by consensus in a process involving at least four of the authors. 
In addition, as shown in Table 3, we adopted the recommended procedures for ensuring rigour in casestudy analysis (Gilson et al., 2011).

\begin{tabular}{|c|c|}
\hline \multicolumn{2}{|l|}{ PRINCIPLE } \\
\hline $\begin{array}{l}\text { Prolonged } \\
\text { engagement }\end{array}$ & $\begin{array}{l}\text { We spent at least two weeks in each of the } 10 \text { case-study districts. Multiple } \\
\text { on-site visits were made to facilities hosting transitioned health workers and } \\
\text { spent engaging in informal discussions with facility in-charges, conducting } \\
\text { formal, face-to-face interviews with multiple informants, reviewing } \\
\text { documents and formal reports relating to the PEPFAR transition process. . }\end{array}$ \\
\hline Use of theory & $\begin{array}{l}\text { We adopted the meta-theoretical Consolidated Framework for } \\
\text { Implementation Research (CFIR) as a guiding conceptual framework for this } \\
\text { study. }\end{array}$ \\
\hline $\begin{array}{l}\text { Case } \\
\text { selection }\end{array}$ & $\begin{array}{l}\text { We selected } 10 \text { (out of } 87 \text { ) districts in Uganda that received PEPFAR Human } \\
\text { Resources for Health support. We selected eight districts with the highest } \\
\text { absorption rates of PEPFAR health workforce and two with the lowest } \\
\text { absorption rates. }\end{array}$ \\
\hline Sampling & $\begin{array}{l}\text { In line with the multi-level analysis lens of the CFIR framework, we selected } \\
\text { participants from national-level actors (e.g. high-level central government } \\
\text { ministry actors) sub-national actors (e.g. District Health Teams and Regional- } \\
\text { based PEPFAR agencies) and facility-level participants (Hospital } \\
\text { Administrators, Head Nurses). Selected participants span across the policy \& } \\
\text { planning, programmatic and implementation spectrums. }\end{array}$ \\
\hline $\begin{array}{l}\text { Multiple } \\
\text { methods }\end{array}$ & $\begin{array}{l}\text { Multiple methods were used including face-to-face interviews, focus group } \\
\text { discussions with transitioned health workers, secondary analyses of (HRiS) } \\
\text { human resources information system data bases, document review and } \\
\text { informal engagements with District Health Teams. }\end{array}$ \\
\hline Triangulation & $\begin{array}{l}\text { Case studies were constructed based on multiple data sources (e.g. } \\
\text { interviewee data, document review and respondent in-put such as with } \\
\text { transitioned health workers themselves). }\end{array}$ \\
\hline $\begin{array}{l}\text { Negative } \\
\text { case analysis }\end{array}$ & $\begin{array}{l}\text { Emergent themes that contradicted initial assumptions and the theory } \\
\text { underpinning the study were identified. }\end{array}$ \\
\hline $\begin{array}{l}\text { Peer } \\
\text { debriefing } \\
\text { and } \\
\text { support }\end{array}$ & $\begin{array}{l}\text { Data analysis at each of the four stages involved a team-based process } \\
\text { involving at least three authors. Across-case analyses were agreed upon by } \\
\text { consensus involving all authors. }\end{array}$ \\
\hline $\begin{array}{l}\text { Respondent } \\
\text { validation }\end{array}$ & $\begin{array}{l}\text { The initial synthesis report by the investigators was presented before the } \\
\text { broad-based Human Resources for Health Technical Working Group (TWG) of } \\
\text { Uganda's Ministry of Health for their in-put based on their combined } \\
\text { experience in the focus area. }\end{array}$ \\
\hline
\end{tabular}

\section{Results}

The identified facilitators and barriers to health worker transition emerging from this study are presented based on the five CFIR-derived domains; a) Process of Implementation b) Characteristics of the intervention b) Inner setting c) Outer setting and d) Characteristics of Individuals. 


\section{Process of Implementation}

Table 5 shows the milestones in the process of implementation of the health worker transition process. Implementation happened at three major levels; a) national-level policy planning and coordination b) Subnational level programmatic supervision c) Facility-level implementation.

\begin{tabular}{|l|l|}
\hline Table 5: Milestones in the HW transition implementation process \\
\hline $\begin{array}{l}\text { Level \& } \\
\text { Stakeholders }\end{array}$ & Key actions \\
\hline National & MoU between PEPFAR and GoU \\
& $\begin{array}{l}\text { Harmonization of salaries } \\
\text { Inter-sector transition meetings around a road map } \\
\text { Developing a transition road map }\end{array}$ \\
& Joint Planning by regionally-based IPs \& District actors. \\
& Determining district HRH needs \\
& Wage bill analysis \\
& Health worker recruitment and deployment \\
\hline Health facility level & Health worker orientation \\
& HW performance management during the contract phase \\
\hline
\end{tabular}

\section{National-level stakeholder engagement and transition planning}

At the national-level the process involved consensus building meetings between PEPFAR and Government of Uganda (GoU) high-level actors around absorption of the recruited workforce after phasing out of support. This culminated in a formal Memorandum of Understanding (MoU) between the two parties. The MoU stipulated that PEPFAR would provide funds for the recruitment process and salary support for the initial 2 years and GoU would subsequently enroll the recruited health workers on the public sector payroll as soon as fiscal space allowed. Inter-sector meetings were convened incorporating the relevant line Ministries of Health, Finance and Public Service. PEPFAR was represented by its overall national coordinating agency-an international NGO, which consulted with relevant program officers at the United States embassy in Uganda. In 2013, a health worker transition implementation plan and road map was jointly agreed through a consultative process involving the two parties. Salary harmonization was key point whereby PEPFAR would pay the recruited workforce (during their two-year contract phase) salaries that were equivalent to public sector salary scales. With the exception of payment of a housing (accommodation) allowance to the contract workforce, PEPFAR's pay structure was well aligned with that of the Uganda Government. 
The PEPFAR national coordinating agency continually monitored the transition process and regularly shared insights and progress reports with Ministry of Health's Human Resources for Health Technical Working Group (TWG).

At the district-level, regionally-based PEPFAR implementing partner (IPs) organizations in the 87 focusdistricts in Uganda held transition planning meetings that engaged district-level actors such as District Health Teams, Chief Administrative Officers (CAOs) and District Human Resource Officers as well as District Service Commissions (DSCs) which make personnel selection decisions. During such meetings, a transition road map at the district-level and the roles of the varied stakeholders were agreed upon. District health teams in conjunction with District Human Resources Offices determined the health worker cadres to be recruited based on the needs of individual districts. Table 4 shows that the bulk of health workers recruited across case-study districts were midwives, nurses and clinical officers. These vacancies were advertised in national newspapers and through district and health facility notice boards. The processes of initial formal recruitment were led by the districts with the financial support of PEPFAR provided through its regionally-based IPs. Across all districts, contract staff were vetted by the District Service Commissions to ensure that they met the Uganda public service standards for recruitment. The IPs managed contracts and payrolls during the two-year contract phase for the transition workforce. In most of the 87 focus-districts an independent PEPFAR contractor was mentioned as the personnel contracts and payroll management agency. The District Health Teams together with IPs monitored performance of contract health workers through instruments such as time sheets which were a basis for approving salaries and later on absorption.

Table 4: Cadres of health workers transitioned from PEPFAR to Government of Uganda

\begin{tabular}{lrr}
\hline HEALTH WORKER CADRE & No. of transitioned HWs & \% by HW cadre N=694 \\
\hline Enrolled Nurse & 275 & 39.6 \\
Enrolled Midwife & 204 & 29.4 \\
\hline Medical Laboratory Technician & 54 & 7.8 \\
\hline Medical Clinical Officer & 50 & 7.2 \\
\hline Biostatistician & 35 & 5.0 \\
\hline Medical Officer & 30 & 4.3 \\
\hline Nursing Officer Nurse & 14 & 2.0 \\
\hline Medical Laboratory Technologist & 13 & 1.9 \\
\hline Enrolled comprehensive Nurse & 8 & 1.2 \\
\hline Nursing Officer Midwife & 6 & 0.9 \\
\hline Dispenser & 3 & 0.4 \\
\hline Pharmacist & 1 & 0.1 \\
\hline Medical Records Assistant & 1 & 0.1 \\
\hline Laboratory Assistant & 0 & 0.0 \\
\hline Anesthetic Officer & 0 & 0.0 \\
\hline Total & $\mathbf{6 9 4}$ & $\mathbf{9 9 . 9}$ \\
\hline
\end{tabular}


At the facility-level, contract staff were oriented in public service structures and processes by their immediate supervisors. The district health teams and facility service managers were instrumental in providing supervision and appraisal of contract staff. This formed the basis of selection of health workers on contract who were to be absorbed onto the public pay roll.

\section{Characteristics of the intervention}

District wage bill budget analysis support

Technical support for district wage bill analyses was extended by the coordinating PEPFAR implementing organization to districts. This was reported as a facilitator for HW transition in 'high absorber' districts. Although there was a widely held perception, among actors within the district administrations that their budgets could not accommodate any new personnel recruitments, technical support in scrutinizing district wage bills revealed unutilized funds in the wage bill that were subsequently deployed to absorbing the contract workforce in the transition MOU with PEPFAR.

'PEPFAR helped us analyze the wage bill budget. There was some confusion with the Ministry of Public service and Ministry of Health and here at the district. We were in the dark. So, PEPFAR came and analyzed and found that we had a balance (funds for salaries) which we were not using. At least we would find there was something (fiscal space) for recruitments' [KII, District Official Iganga].

Conversely, in 'low absorber' districts participants reported that they did not receive technical support in wage bill analyses. Hence, donor support in wage bill analyses emerged as a distinguishing feature between the two categories of 'high absorber' and 'low absorber' districts.

However, Fig. 1 shows that even across the 'high absorber' districts there were still a significant number of contract staff who were not enrolled onto the public sector payroll. Wage bill ceilings limited the ability of districts to absorb a higher number of contract staff.

We observed that 'low absorber' districts had a higher number of their contract staff seconded to PNFPs (Private Not-For-Profits) such as mission hospitals which had an even weaker absorption capacity (at $30 \%$ ) compared to district local governments (at 55\%).

'The absorption has been very slow in PNFPs because these did not have money to absorb them. Most PNFPs were comfortable offering services with low cadre staff and do not have a budget to hire high cadre staff. But PEPEFAR hired these staff for the HIV response but health facilities do not have income to maintain them. So transition in PNFP is very challenging' (KII, National-Level official)

Figure 2 shows the number of health workers absorbed between 2012 and 2017. Secondary analyses of HRIS and PEPFAR data bases revealed that over 500 of the recruited workforce were not absorbed in GoU service after transition. Across case-study districts, a number of health workers left government service before they were formally absorbed. In the focus group discussions, health workers indicated that variable delays in accessing the public payroll after their 2-year PEPFAR contracts had run out, a lack of 
private accommodation (especially in rural Northern Uganda) and challenging work environments such as chronic stock-outs of supplies contributed to the reduction of the pool of workforce available for absorption. Many opted for alternative employment - mostly private sector providers.

Support in convening district personnel recruitment committees

PEPFAR support helped in unlocking the inherent and long-standing organizational barriers to expansion of the existing district health workforce in 'high absorber' cases. A lack of basic operational funds for supporting the lengthy procedures required for hiring new staff was a constraint raised across all casestudy districts. District Service commission (DSCs) are standing committees that make personnel selection decisions and are meant to sit every three months. However, the DSCs were widely reported to be dysfunctional owing to a chronic inability to raise monetary allowances for paying the non-full time DSCs which are comprised of retired senior public servants. Running district job adverts in national newspapers was said to be prohibitively expensive which further impeded personnel recruitments. PEPFAR provided the necessary funding to kick-start recruitment processes in form of paying for newspaper job adverts, providing monetary allowances to DSCs and sent observers to meetings where job interviews were conducted which enhanced transparency and objectivity in the selection processes. United States embassy program officers in Uganda reported that PEPFAR had committed $\$ 9,333,891$ for the health worker transition programme in 2012 alone and an additional \$4,494,149 in 2015. Districtlevel informants described the nature of PEPFAR support they received:

'PEPFAR helped with providing the recruitment funds. It provided sitting allowances to enable District Service Commissions to convene as well as providing allowances to committee members during the interview of candidates. They facilitated most of the activities utilizing our own technical staff' (KII, District Official, Sheema District).

\section{Transparency in recruitment of the transitioned health workforce}

A number of health workers reported that before the PEPFAR intervention, DSCs had a reputation of questionable objectivity in the selection of personnel due to a widely-held perception that nepotism and bribery were common in district personnel recruitment decisions. Given this context, the selection of PEPFAR-supported health workers through transparent and merit-based processes lent special legitimacy to transition workforce which enhanced their absorption prospects into public service. District and facilitylevel managers perceived PEPFAR-supported personnel as having been recruited through rigorous and objective procedures.

I look at it as a good strategy for recruiting staff. This issue of our local politics of you are going to recruit this one's daughter (nepotism), you are going to solicit bribes... those ones didn't surface anywhere. It was a purified process that government didn't have any reason whatsoever to object to their absorption. Someone recruited by an NGO interested in health you can't doubt their qualifications, you can't doubt 
their capabilities and then I think it also eliminated this issue of tribalism (ethnic biases) in recruitments [KII, District Official, Tororo].

The transitioned workforce was perceived as competent and suitable for absorption into government service. The two-year contract phase funded by PEPFAR allowed facility-level managers to identify resilient and dependable HWs for absorption. In addition, this phase also provided HWs with an opportunity to be inducted and initiated into government systems and work environments.

'When they came the health workers on contract exhibited professionalism in their work. They were good people and immediately, they started working. The quality of service, was realized by the community. I think there is a visible change in the hospital since they came in [KII, District Official, Apac].

\section{Outer setting}

Multi-sectoral engagements in transition process

At an institutional level, multi-stakeholder engagements involving actors at the national, sub-national and facility-levels were identified as a major transition facilitator by participants in 'high absorber' districts. At national-level, PEPFAR was involved in multi-sectoral engagements of high-level actors with authority for approving health worker recruitments in relevant central government sector ministries such as Finance, Public Service and Health.

A transition road map and memorandum of understanding (MoU) was agreed between PEPFAR and sector ministries in which PEPFAR undertook to provide salary support of the new workforce recruits for two years while Uganda Government would enroll these health workers onto the public sector payroll as soon as fiscal space permitted. This facilitated buy-in from influential actors in sector ministries. At the sub-national level, PEPFAR implementing organizations in varied geographic sub-regions spearheaded engagement with sub-national actors such as District Health Officers and Chief Administrative Officers (CAOs). MoUs was signed between regionally-based PEPFAR implementing organizations and the districts under their purview.

'We had several interactions. Ministry of Health invited us. As a district, we are supposed to implement Ministry of Health policies. The policy was such that PEPFAR would recruit those health workers on contract and with time, the districts, with help of Ministry of Health and Finance would avail a wage bill to absorb them. So that was the understanding. First between Ministry of Health and PEPFAR, then we as implementing partners as districts and local government. That's how we came on board' (KII District Official Sheema).

Crucially, PEPFAR worked within established Uganda Government recruitment process and structures. Districts determined the cadres that would be hired based on their needs. District Service Commissions (DSCs) made the ultimate hiring decisions. This lent legitimacy to the cohort of health workers recruited with PEPFAR support. 
'All recruitment of contract staff was done by district service commissions (DSCs). So when it comes to absorption, such health workers are regularized because they were already recognized as legitimate staff hired through competent structures' [KII, National-Level official].

\section{Inner setting}

Prioritization of health workers in district personnel recruitments

The prioritization of health workers in district personnel recruitments was a key distinguishing feature between 'high absorbers' and 'low absorbers' cases. In 'high absorber' districts such as Kasese and Sheema, participants were unequivocal in relaying the notion that their district administrations deliberately prioritized the health workforce in recruitments. In the 'high absorber' cases, whenever some fiscal space in the district wage bill emerged, slots for health workers were 'ring-fenced' as the overall priority- taking the shape of an informal recruitment policy.

In fact we had to trade off some cadres, those ones who were not extremely needed or useful we had to keep them off in order to bring in the more useful staff like the midwives and clinical officers' (KII, District Official, Apac)

'You may have the wage bill but how are you going to prioritize the cadres of peoples you are going to recruit? You may say my entire Health Centre Ils need a security guard. You may recruit like 20 porters. I know they are needed there but is it a priority? (KII, District Official, Sheema).

Although we found that 'high absorber' districts prioritized health workers in their wage bill, national-level informants reported that this was further reinforced by formal written memos from central government Ministries of Public Service and Health to the district political and technical leadership asking that they prioritize the absorption of PEPFAR-supported workforce in the available wage bills. These memos were written in March 2013 as a result of the protracted engagements by PEPFAR and high-level actors in sector ministries which were in line with the jointly developed health worker transition road map.

\section{Characteristics of Individuals}

\section{Presence of transition 'Champions'}

The presence or absence of transition 'champions' differentiated between 'high absorber' and 'low absorber' districts.

Whereas 'high absorber' districts reported the presence of internal transition 'champions', their absence in participant discourses in 'low absorber' districts was unmistakable.

Transition 'champions' were individuals who went above and beyond the call of duty of their positions to promote the absorption of health workers onto the public pay roll. These champions were reported at both the district and facility-levels. The presence of champions at multiple levels created synergies in promoting health worker absorption in 'high absorber' districts. The frequently cited champions include influential actors such as Chief Administrative Officers (CAOs) of host districts, District Health Officers 
(DHOs) and Hospital administrators who actively pushed for the recruitment and absorption of health workers and enrollment on the government payroll.

'We had a smooth transition because the team in XXX (District) is very proactive. They don't operate like they are in government. The CAO (Chief Administrative Officer) was an experienced man so he was quick to come in and push the recruitment process along. Much more than it normally is. The District Human Resource Officer was very active. They did their work in a timely way and actively pushed to have the HWs absorbed. Issues of health workers were prioritized. Actually, the first batch of health workers we even gave them appointment letters before their contracts were over' [KIl, District Official, Iganga].

Champions tirelessly worked to expedite processes in the context of the typically lengthy administrative procedures in the Ugandan public sector. They acted as 'persistence enhancers' for health workers and even appropriated district finances to create 'stop-gap' monetary allowances for health workers before they were able to access the public payroll.

Actors at the facility-level were frequently cited as transition champions. Facility in-charges were motivated by a need to avoid losing skilled health workers who had been posted at their health facilities as contract staff. As such, they were instrumental in ensuring timely appraisal of contract health workers but also engaged in active follow-up with the District Service Commissions at the district administration headquarters for absorption of health workers to avoid losing their contract staff. Facility in-charges in 'high absorber' districts actively engaged their transition workforce in activities such as surgical camps and community outreaches to enable them secure some field monetary allowances to sustain them as they awaited enrolment on the payroll which was characterized by prolonged delays in several of the case-study districts.

'The salaries could delay for two to three months.

We have PHC (primary health care) funds earmarked to this facility. We used some of this to buy them basics such as soap and sugar that could also help them to persist and endure' [KII, Facility in-charge, Nwoya District].

\section{Discussion}

We conducted a multiple case-study of 10 districts in Uganda to better understand why they had variations in absorption rates of the health workforce transitioned from PEPFAR payroll support. We found distinguishing features between the two 'low absorber' districts and the eight 'high absorber' districts. We found that in the latter cases, conducting a wage bill analysis of district budgets to discover unutilized funds, the presence of transition 'champions' and prioritizing health workers in the available district wage bill differentiated them from the 'low absorber' districts where these attributes were absent. At an institutional level, multi-stakeholder and multi-sectoral engagements, agreeing on a joint transition road map and PEPFAR's alignment with Uganda government pay scales and recruitment processes enabled over 694 health workers to be added to the public sector payroll. However, limitations in district 
wage bills, prolonged delays in enrollment onto the public sector payrolls and a lack of accommodation for transition health workers were common across all districts.

\section{Implementation research and strategies for effective donor transitions}

The PEPFAR health worker transition case-studies documented here offer implementation research lessons on effective donor transition for global health initiatives and bilateral development partners. We observe that, in this particular study, PEPFAR's transition model conforms with three (of the six) donor transition 'good practices' which were earlier proposed (Vorgus \& Graff, 2014). More specifically, we found that agreeing on a joint transition road map, communicating early about the transition intentions and aligning with Uganda government salary scales and recruitment procedures enhanced health workforce absorption. In our analysis of participant discourses, we noted some but limited monitoring and evaluation mechanisms in the health worker transition road map and implementation plan which is recommended in the literature. There is a sparse but emerging evidence base on recommended donor transition planning and management in the health sector (Bennett et al., 2015; Burrows et al., 2016; Amaya et al. 2014; Vorgus \& Graff, 2014; Palen et al. 2012).

Although previous studies have noted PEPFAR's strong vertical-orientation in its support for national HIV responses, often provided within parallel structures to those of donor-recipient governments (Windisch et al.

2011; Luboga et al., 2016; Ssengooba et al. 2017), we document a unique case-study of a less vertical PEPFAR aid approach which resulted in increased Uganda Government budgetary allocation for expanding the health workforce in districts without which support, the absorption of 694 health workers might not have been triggered. A notable finding of this study was that PEPFAR's multi-sectoral engagement of high-level actors in Uganda generated buy-in from the influential Ministry of Finance which technically commits votes in the national budget. Although there are mounting calls for engagement of Ministries of Finance in expanding fiscal space for health (Whyle and Olivier, 2016), there is little research documenting 'catalyst' engagements that result in tangible outcomes especially with regard to addressing the human resources for health crisis. Our study suggests that sustained engagements with the Ministry of Finance and other line ministries helped 694 health workers transition to public sector payrolls. However, Bennett et al. 2018 highlight the influence of external development partners in providing the financial impetus for initiating multi-sectoral collaborations, and note that local actors may not have this leverage or obtaining organizational cultures may not be supportive "In LMIC, a related factor concerns the role of external development partners. Multi-sectoral action that has strong external support likely has better access to financial resources, but may suffer from limited local ownership (and hence perhaps low motivation), and conceivably organizational blue prints that do not align with ways of doing business in country."

A review article assessing health-system strengthening (HSS) interventions by Adam et al., 2009, recommends the application of a 'systems thinking' lens in designing HSS interventions that engage and 
cut across the six 'building blocks' or sub-components of a health-system.

In reflecting on participants' discourses in this study, we observe that PEPFAR's Human Resources for Health support in Uganda and the subsequent donor transition effort engaged with at least four intersecting health system 'building blocks' namely; health financing, health information systems, leadership and governance and health workforce (Mounier-Jack et al.

2014; van Olmen et al. 2014; Zakumumpa et al. 2018; Mutale et al. 2014).

In this study we found that Private Not-for-Profit (PNFP) facilities had lower absorption rates of the workforce transitioned from PEPFAR support at (30\% absorption) compared to district local governments with a $55 \%$ absorption rate.

Our study adds to accumulating calls for government support to the private sector in bolstering human resources for health including in payroll support (Zakumumpa et al. 2016) and the need for increased engagement by donors and governments of the private sector in moves towards universal health coverage (Ssenyonjo et al. 2019; Montagu et al. 2016; Wilhelm et al. 2020).

The adopted five domains of the CFIR framework were helpful in providing a broad deductive framework for our overall synthesis and interpretation of study findings as well as in their presentation-we note that although the framework categorizes into five domains, some of our findings appeared to cut across more than one domain. For instance, we found that the prioritization of health workers in district wage bill commitments derived from 'inner setting' priority-setting but was re-enforced by 'outer setting' factors such as written memos from central government line ministries. In this sense, our study suggests some dynamic interactions in facilitators of health worker transition in Uganda. The notion of dynamic interactions in factors influencing the implementation and sustainability of health program interventions has been observed in previous studies (Stirman et al. 2012; Durlak \& DuPre, 2008; Zakumumpa et al., 2018)

\section{The challenges of workforce recruitments in decentralized settings}

This study illuminates the dysfunction that underpins recruitment freezes in decentralized settings in Uganda that ranges from insufficient basic operational funds for convening recruitment bodies, limited expertize in wage bill analysis, district workforce budget caps and common perceptions of nepotism and corruption in recruitment decisions. Previous studies have reported the constraints encountered in health workforce recruitments in decentralized systems in Uganda, Ghana, Tanzania and Nigeria (Ssengooba et al. 2007 ; Sumah and Baatiema 2019; Munga et al. 2009; Mbemba et al. 2016; Sakyi et al. 2011; Frumence et al. 2013).

Our study does however highlight the potential influence of 'change agents' in driving health system reform and in unlocking fiscal space for health in a resource-constrained setting. At an institutional level, we found that the presence of transition 'champions' at multiple levels including within district governance systems but also at the facility-level was a key enabler of increasing budgetary allocations 
for expanding the health workforce in Uganda. We find that PEPFAR support had a 'trigger effect' that synergized the role of internal 'champions' in promoting health system strengthening. In influencing health system strengthening in Uganda, PEPFAR can be said to have been acting as a catalyst. The role of 'external change agents' is recognized in implementation research (Means et al. 2020). Our findings add to the accumulating evidence base pointing to the influence of leadership and governance on healthsystems development and outcomes in decentralized settings (Schneider et al.,2019; Mitchell \& Bossert, 2010, Abimbola et al., 2019).

\section{Conclusion}

Overall, PEPFAR's Human Resource for Health support acted as a catalyst for increasing GoU and facilitylevel budget allocations towards expanding the health workforce in focus districts in Uganda. Our casestudies offer implementation research lessons on effective donor transition and insights into pragmatic strategies for expanding fiscal space for health in a low-income setting.

\section{Declarations}

\section{Acknowledgements}

This paper was written under the auspices of a post-doctoral research fellowship at the University of the Western Cape, School of Public Health in South Africa which was supervised by Prof Helen Schneider and funded by Belgian Development Cooperation through the Institute of Tropical Medicine Antwerp (Grant Ref: FA4 DGD-ITM 2017-2020).

We gratefully acknowledge funding for data collection of Round One for this study from the United States Agency for International Development (USAID) under the terms of cooperative agreement no. AID-OAA-A15-00046 (2015-2020) in partnership with The U.S. President's Emergency Plan for AIDS Relief.

We are very thankful to llyse Stempler and Sarah Scheening for their helpful comments and suggestions during implementation of this study.

\section{Competing interests:}

The authors declare they have no competing interests.

\section{Ethical approval}

Ethical approval to conduct the study was granted by Mildmay Uganda Research Ethics Committee(MUREC) under instrument: REC REF-0604-2018. MUREC is accredited by the Uganda National Council of Science and Technology.

\section{References}


1. Abimbola, S., Baatiema, L. and Bigdeli, M., 2019. The impacts of decentralization on health system equity, efficiency and resilience: a realist synthesis of the evidence. Health policy and planning, 34(8), pp.605-617.

2. Adam, T., Hsu, J., De Savigny, D., Lavis, J.N., Røttingen, J.A. and Bennett, S., 2012. Evaluating health systems strengthening interventions in low-income and middle-income countries: are we asking the right questions?. Health policy and planning, 27(suppl_4), pp.iv9-iv19.

3. Alonso-Garbayo, A., Raven, J., Theobald, S., Ssengooba, F., Nattimba, M. and Martineau, T., 2017. Decision space for health workforce management in decentralized settings: a case study in Uganda. Health Policy and Planning, 32(suppl_3), pp.iii59-iii66.

4. Amaya, A.B., Caceres, C.F., Spicer, N. and Balabanova, D., 2014. After the Global Fund: who can sustain the HIV/AIDS response in Peru and how?. Global Public Health, 9(1-2), pp.176-197.

5. Awortwi, N., 2010. The past, present, and future of decentralisation in Africa: a comparative case study of local government development trajectories of Ghana and Uganda. International journal of public administration, 33(12-13), pp.620-634.

6. Bennett, S., Rodriguez, D., Ozawa, S., Singh, K., Bohren, M., Chhabra, V. and Singh, S., 2015. Management practices to support donor transition: lessons from Avahan, the India AIDS Initiative. BMC health services research, 15(1), p.232.

7. Bennett, S., Glandon, D. and Rasanathan, K., 2018. Governing multisectoral action for health in lowincome and middle-income countries: unpacking the problem and rising to the challenge. $B M J$ Global Health, 3(Suppl 4), p.e000880.

8. Bossert, T.J. and Beauvais, J.C., 2002. Decentralization of health systems in Ghana, Zambia, Uganda and the Philippines: a comparative analysis of decision space. Health policy and planning, 17(1), pp.14-31.

9. Bossert, T.J. and Mitchell, A.D., 2011. Health sector decentralization and local decision-making: decision space, institutional capacities and accountability in Pakistan. Social science \& medicine, 72(1), pp.39-48.

10. Bulthuis, S.E., Kok, M.C., Amon, S., Agyemang, S.A., Nsabagasani, X., Sanudi, L., Raven, J., Finn, M., Gerold, J., Tulloch, O. and Dieleman, M.A., 2020. How district health decision-making is shaped within decentralised contexts: A qualitative research in Malawi, Uganda and Ghana. Global public health, pp.1-16.

11. Burrows, D., Oberth, G., Parsons, D. and McCallum, L., 2016. Transitions from donor funding to domestic reliance for HIV responses. Recommendations for transitioning countries. Nairobi: APM Global Health.

12. Damschroder, L.J., Aron, D.C., Keith, R.E., Kirsh, S.R., Alexander, J.A. and Lowery, J.C., 2009. Fostering implementation of health services research findings into practice: a consolidated framework for advancing implementation science. Implementation science, 4(1), pp.1-15.

13. Durlak, J.A. and DuPre, E.P., 2008. Implementation matters: A review of research on the influence of implementation on program outcomes and the factors affecting implementation. American journal 
of community psychology, 41(3-4), p.327.

14. Fereday, J. and Muir-Cochrane, E., 2006. Demonstrating rigor using thematic analysis: A hybrid approach of inductive and deductive coding and theme development. International journal of qualitative methods, 5(1), pp.80-92.

15. Freer, J., 2017. Sustainable development goals and the human resources crisis. International health, 9(1), pp.1-2.

16. Frumence, G., Nyamhanga, T., Mwangu, M. and Hurtig, A.K., 2013. Challenges to the implementation of health sector decentralization in Tanzania: experiences from Kongwa district council. Global health action, 6(1), p.20983.

17. Gilson, L. and World Health Organization, 2012. Health policy and systems research: a methodology reader. World Health Organization.

18. Gilson, L., Hanson, K., Sheikh, K., Agyepong, I.A., Ssengooba, F. and Bennett, S., 2011. Building the field of health policy and systems research: social science matters. PLoS Med, 8(8), p.e1001079.

19. Glaser, B.G. and Strauss, A.L., 1999. Theoretical sampling The discovery of grounded theory: strategies for qualitative research.

20. Gotsadze, G., Chikovani, I., Sulaberidze, L., Gotsadze, T., Goguadze, K. and Tavanxhi, N., 2019. The challenges of transition from donor-funded programs: results from a theory-driven multi-country comparative case study of programs in Eastern Europe and Central Asia supported by the Global Fund. Global Health: Science and Practice, 7(2), pp.258-272.

21. Heller, P.S., 2006. The prospects of creating 'fiscal space'for the health sector. Health Policy and Planning, 21(2), pp.75-79.

22. Henriksson, D.K., Peterson, S.S., Waiswa, P. and Fredriksson, M., 2019. Decision-making in district health planning in Uganda: does use of district-specific evidence matter?. Health research policy and systems, 17(1), p.57.

23. Jaskiewicz, W., Oketcho, V., Settle, D., Frymus, D., Ntalazi, F., Ezati, I. and Tulenko, K., 2016. Investing in the health workforce to increase access to and use of HIV and AIDS services in Uganda. AIDS (London, England), 30(13), p.N21.

24. Liwanag, H.J. and Wyss, K., 2018. What conditions enable decentralization to improve the health system? Qualitative analysis of perspectives on decision space after 25 years of devolution in the Philippines. PLoS One, 13(11), p.e0206809.

25. Luboga, S.A., Stover, B., Lim, T.W., Makumbi, F., Kiwanuka, N., Lubega, F., Ndizihiwe, A., Mukooyo, E., Hurley, E.K., Borse, N. and Wood, A., 2016. Did PEPFAR investments result in health system strengthening? A retrospective longitudinal study measuring non-HIV health service utilization at the district level. Health policy and planning, 31(7), pp.897-909.

26. Lwanga, M., Lakuma, C.P., Sserunjogi, B. and Shinyekwa, I., 2018. Boosting Domestic Revenue Mobilisation in Uganda. EPRC Research Series, 140.

27. Mbemba, G.I.C., Gagnon, M.P. and Hamelin-Brabant, L., 2016. Factors influencing recruitment and retention of healthcare workers in rural and remote areas in developed and developing countries: an 
overview. Journal of Public Health in Africa, 7(2).

28. Means, A.R., Kemp, C.G., Gwayi-Chore, M.C., Gimbel, S., Soi, C., Sherr, K., Wagenaar, B.H., Wasserheit, J.N. and Weiner, B.J., 2020. Evaluating and optimizing the consolidated framework for implementation research (CFIR) for use in low-and middle-income countries: a systematic review. Implementation Science, 15(1), pp.1-19.

29. Micah, A.E., Zlavog, B.S., Chen, C.S., Chapin, A. and Dieleman, J.L., 2018. Donor financing of human resources for health, 1990-2016: an examination of trends, sources of funds, and recipients. Globalization and health, 14(1), p.98.

30. Miles, M.B. and Huberman, A.M., 1994. Qualitative data analysis: An expanded sourcebook. sage.

31. Montagu, D., Goodman, C., Berman, P., Penn, A. and Visconti, A., 2016. Recent trends in working with the private sector to improve basic healthcare: a review of evidence and interventions. Health Policy and Planning, 31(8), pp.1117-1132.

32. Mounier-Jack, S., Griffiths, U.K., Closser, S., Burchett, H. and Marchal, B., 2014. Measuring the health systems impact of disease control programmes: a critical reflection on the WHO building blocks framework. BMC public health, 14(1), p.278.

33. Munga, M.A., Songstad, N.G., Blystad, A. and Mæstad, O., 2009. The decentralisation-centralisation dilemma: recruitment and distribution of health workers in remote districts of Tanzania. BMC international health and human rights, 9(1), p.9.

34. Mutale, W., Bond, V., Mwanamwenge, M.T., Mlewa, S., Balabanova, D., Spicer, N. and Ayles, H., 2013. Systems thinking in practice: the current status of the six WHO building blocks for health system strengthening in three BHOMA intervention districts of Zambia: a baseline qualitative study. BMC health services research, 13(1), p.291.

35. Palen, J., El-Sadr, W., Phoya, A., Imtiaz, R., Einterz, R., Quain, E., Blandford, J., Bouey, P. and Lion, A., 2012. PEPFAR, health system strengthening, and promoting sustainability and country ownership. JAIDS Journal of Acquired Immune Deficiency Syndromes, 60, pp.S113-S119.

36. Proctor, E., Silmere, H., Raghavan, R., Hovmand, P., Aarons, G., Bunger, A., Griffey, R. and Hensley, M., 2011. Outcomes for implementation research: conceptual distinctions, measurement challenges, and research agenda. Administration and Policy in Mental Health and Mental Health Services Research, 38(2), pp.65-76.

37. Resch, S. and Hecht, R., 2018. Transitioning financial responsibility for health programs from external donors to developing countries: key issues and recommendations for policy and research. Journal of global health, 8(1).

38. Sakyi, E.K., 2013. A critical review of the theoretical objectives and practical experiences of decentralization from the perspective of developing African countries. The Journal of African \& Asian Local Government Studies, 2(3), pp.50-78.

39. Schneider, H., George, A., Mukinda, F. and Tabana, H., 2020. District governance and improved maternal, neonatal and child health in South Africa: pathways of change. Health Systems \& Reform, 6(1), p.e1669943. 
40. Ssengooba, F., Namakula, J., Kawooya, V. and Fustukian, S., 2017. Sub-national assessment of aid effectiveness: A case study of post-conflict districts in Uganda. Globalization and health, 13(1), p.32.

41. Ssengooba, F., Rahman, S.A., Hongoro, C., Rutebemberwa, E., Mustafa, A., Kielmann, T. and McPake, B., 2007. Health sector reforms and human resources for health in Uganda and Bangladesh: mechanisms of effect. Human resources for health, 5(1), pp.1-13.

42. Ssennyonjo, A., Namakula, J., Kasyaba, R., Orach, S., Bennett, S. and Ssengooba, F., 2018. Government resource contributions to the private-not-for-profit sector in Uganda: evolution, adaptations and implications for universal health coverage. International journal for equity in health, 17(1), pp.1-12.

43. Stirman, S.W., Kimberly, J., Cook, N., Calloway, A., Castro, F. and Charns, M., 2012. The sustainability of new programs and innovations: a review of the empirical literature and recommendations for future research. Implementation science, $7(1)$, p.17.

44. Sumah, A.M. and Baatiema, L., 2019. Decentralisation and management of human resource for health in the health system of Ghana: a decision space analysis. International journal of health policy and management, 8(1), p.28.

45. Tashobya, C.K., Dubourg, D., Ssengooba, F., Speybroeck, N., Macq, J. and Criel, B., 2016. A comparison of hierarchical cluster analysis and league table rankings as methods for analysis and presentation of district health system performance data in Uganda. Health policy and planning, 31(2), pp.217-228.

46. USAID.2019. Brief Series on Informing HIV workforce Sustainability Planning. A case-study from Uganda. Retrieved 12th November 2020 from: https://hrh2030program.org/informing-hiv-workforcesustainability-planning-a-case-study-from-uganda/

47. Van Olmen, J., Marchal, B., Van Damme, W., Kegels, G. and Hill, P.S., 2012. Health systems frameworks in their political context: framing divergent agendas. BMC Public Health, 12(1), p.774.

48. Vermund, S.H., Sidat, M., Weil, L.F., Tique, J.A., Moon, T.D. and Ciampa, P.J., 2012. Transitioning HIV care and treatment programs in southern Africa to full local management. AIDS (London, England), 26(10), p.1303.

49. Vogus, A. and Graff, K., 2015. PEPFAR transitions to country ownership: review of past donor transitions and application of lessons learned to the Eastern Caribbean. Global Health: Science and Practice, 3(2), pp.274-286.

50. Whyle, E.B. and Olivier, J., 2016. Models of public-private engagement for health services delivery and financing in Southern Africa: a systematic review. Health policy and planning, 31(10), pp.15151529.

51. Wilhelm, J.A., Paina, L., Qiu, M., Zakumumpa, H. and Bennett, S., 2020. The differential impacts of PEPFAR transition on private for-profit, private not-for-profit and publicly owned health facilities in Uganda. Health policy and planning, 35(2), pp.133-141.

52. Windisch, R., Waiswa, P., Neuhann, F., Scheibe, F. and de Savigny, D., 2011. Scaling up antiretroviral therapy in Uganda: using supply chain management to appraise health systems strengthening. 
Globalization and health, 7(1), p.25.

53. Yin, R.K., 2003. Designing case studies. Qualitative Research Methods, pp.359-386.

54. Zakumumpa, H., Bennett, S. and Ssengooba, F., 2017. Modifications to ART service delivery models by health facilities in Uganda in promotion of intervention sustainability: a mixed methods study. Implementation Science, 12(1), pp.1-14.

55. Zakumumpa, H., Dube, N., Damian, R.S. and Rutebemberwa, E., 2018. Understanding the dynamic interactions driving the sustainability of ART scale-up implementation in Uganda. Global health research and policy, 3(1), p.23.

56. Zakumumpa, H., Taiwo, M.O., Muganzi, A. and Ssengooba, F., 2016. Human resources for health strategies adopted by providers in resource-limited settings to sustain long-term delivery of ART: a mixed-methods study from Uganda. Human resources for health, 14(1), p.63.

\section{Figures}

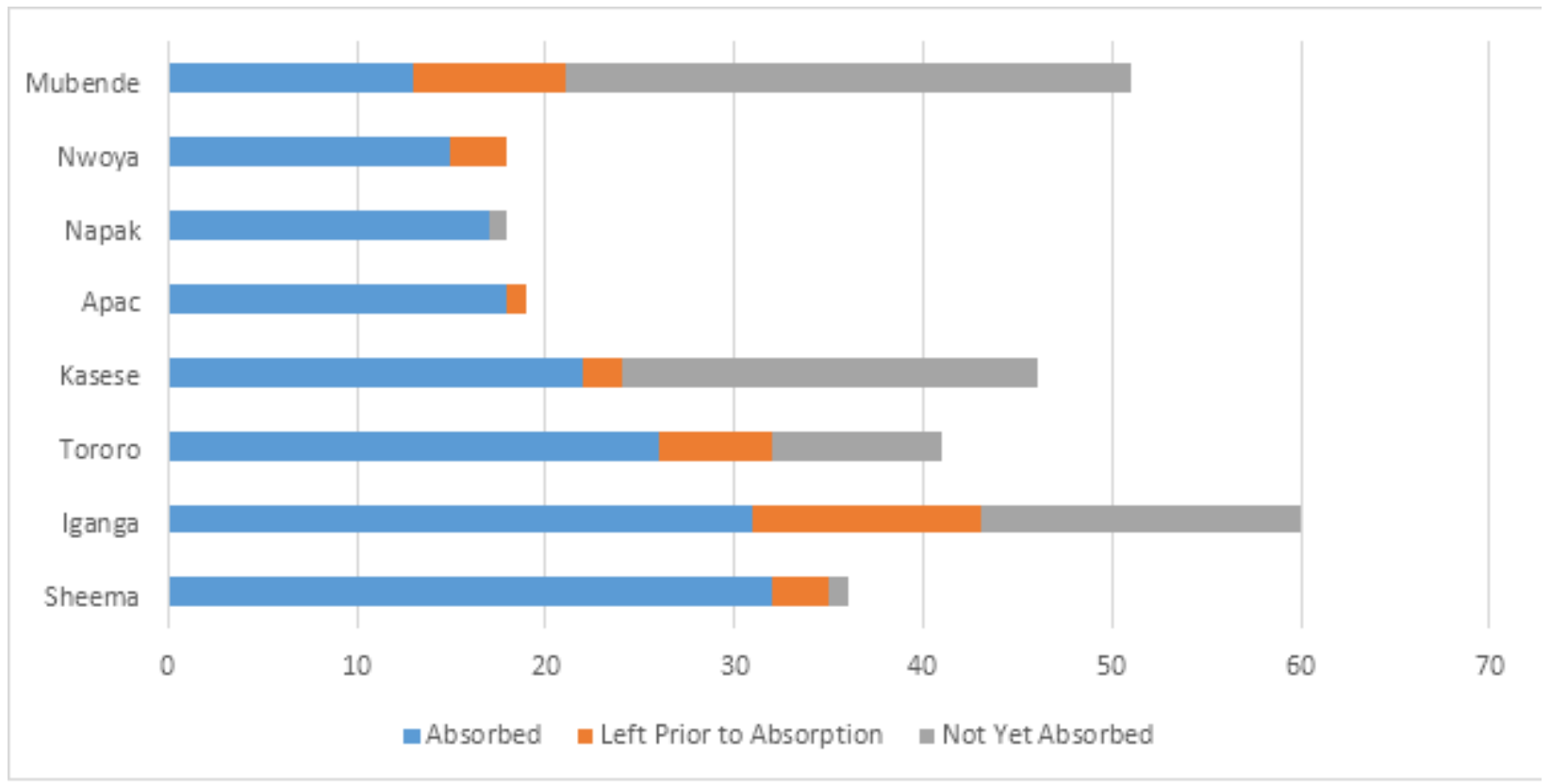

\section{Figure 1}

Number of Health workers absorbed in 'high absorber' districts. 
Figure 2: Num ber of Health workers transitioned between 2014 and 2017

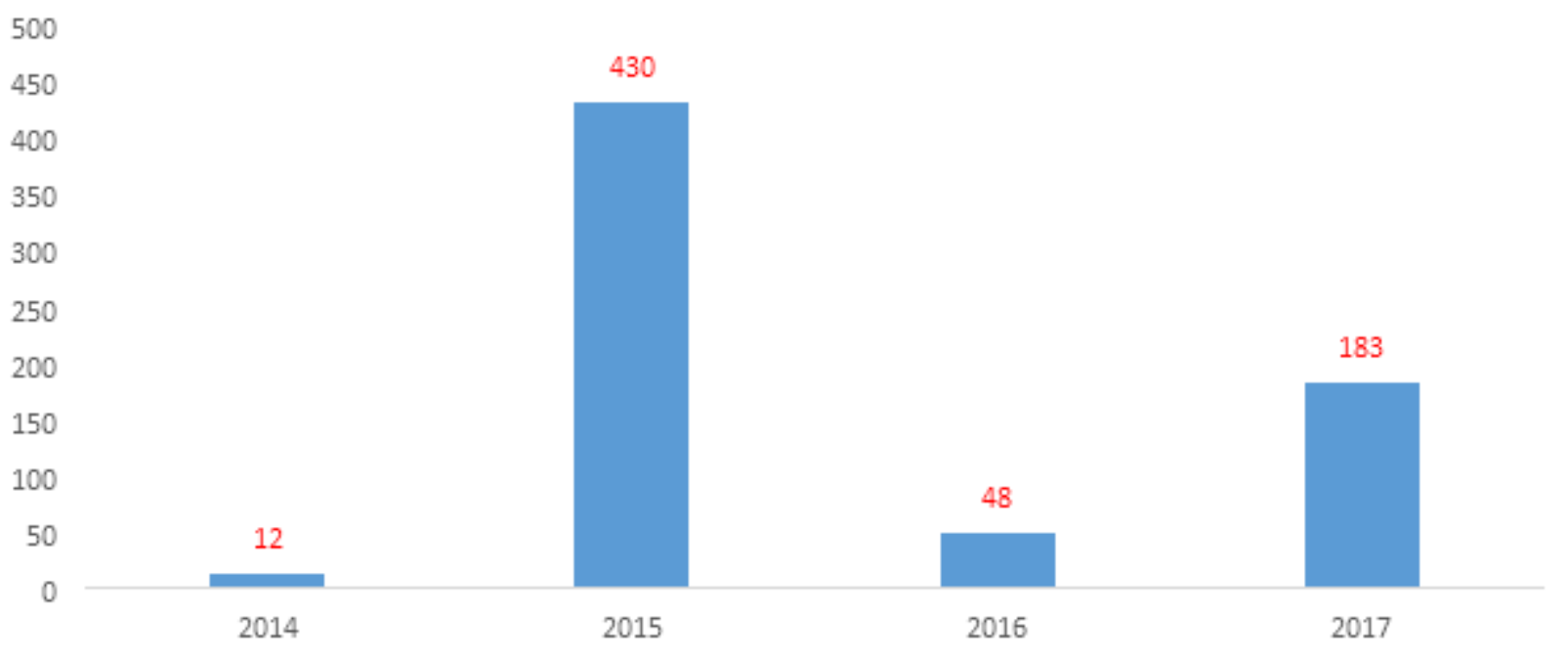

Figure 2

Number of Health workers transitioned between 2014 and 2017 